\title{
Referentes curriculares para la toma de decisiones en materia de planes de estudio de educación superior
}

\author{
Curricular References for Decision-Making in Higher Education Study Plans
}

\section{Referências curriculares para a tomada de decisão em relação aos currículos do ensino superior}

\author{
Evelyn Chen-Quesada \\ Universidad Nacional \\ Centro de Investigación y Docencia en Educación \\ Heredia, Costa Rica \\ echenque@gmail.com \\ https://orcid.org/0000-0002-5280-3134 \\ Silvia Elena Salas-Soto \\ Universidad Nacional \\ Centro de Investigación y Docencia en Educación \\ Heredia, Costa Rica \\ ssalass92@gmail.com \\ https://orcid.org/0000-0002-1629-140X
}

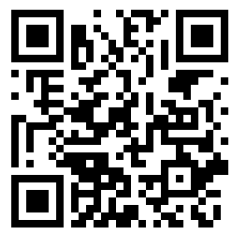

\begin{abstract}
Recibido - Received • Recebido: 04 / 12 / 2017
Corregido - Revised • Revisado: 13 / 12 / 2018

Aceptado•Accepted -Aprovado: 19 / 12 / 2018
\end{abstract}

\begin{abstract}
Resumen: El objetivo de este artículo es ofrecer a los entes gestores del currículo de instituciones de educación superior, la concepción de currículo universitario, los referentes curriculares por considerar en la toma de decisiones requeridas para la implementación reflexiva de los planes de estudio, y los retos de la educación superior ante las demandas de la sociedad actual. Dado que esta es una tarea que involucra aportes desde la teoría curricular y la disciplina propia del objeto de estudio que aborda un plan de estudios en particular, el contenido se convierte en una herramienta que promueve desde el campo teórico, el trabajo transdisciplinario e interdisciplinario dinámico, que podría aportar en la adopción de enfoques curriculares que apoyan la práctica consciente y remozada de la educación superior. El estudio presenta los aportes y clasificación de 22 enfoques curriculares de especialistas tales como Eisner y Wallance (1974), Molina (1997), Grundy (1998), Posner (1998) y Sacristán (2010), quienes organizan el conocimiento según los distintos referentes y, además, se actualizan según las nuevas tendencias, esto por cuanto el currículo universitario está sujeto a renovación según las necesidades de los contextos sociales en los que se desempeña. Entre los principales hallazgos se destaca que la comprensión de cada enfoque curricular brinda luces sobre las nuevas propuestas de planes de estudios más afines a los retos que plantea la sociedad y que son necesarios para avanzar hacia perfiles profesionales integrales y con salidas laborales reales. Además, el estudio subraya que los nuevos planes de estudio universitarios deben contener la visión de lo físico, social y socioafectivo con altos niveles de calidad, equidad, uso de tecnologías, un claro acercamiento de las disciplinas que promuevan la participación activa de estudiantes, personal académico, entes empleadores y
\end{abstract}


doi: http://dx.doi.org/10.15359/ree.23-3.7

URL: http://www.una.ac.cr/educare

CORREO: educare@una.cr

otros, que promuevan propuestas curriculares interdisciplinarias y transdisciplinarias. La principal implicación de la investigación es brindar a personal académico e investigador un referente basado en criterios de selección histórica y actual de los enfoques curriculares que pueda ser consultado en futuros estudios en materia de calidad de la formación profesional universitaria.

Palabras claves: Educación Superior; enfoques curriculares; planes de estudio; toma de decisiones; trabajo interdisciplinario.

Abstract: This article aims to offer the curriculum managers of Higher Education institutions the conception of the university curriculum, the curricular references to be considered in the decisionmaking required for the reflective implementation of the curricula, and the challenges of the Higher Education before the demands of today's society. Since this is a task involving contributions from the curricular theory and the discipline proper to the object of study that addresses a particular curriculum, the content becomes a tool that promotes, from the theoretical field, the transdisciplinary and dynamic interdisciplinary work; this work can contribute to the adoption of curricular approaches that support the conscious and renewed practice of Higher Education. The study presents the contributions and classification of 22 curricular approaches of specialists such as Eisner and Wallance (1974), Molina (1997), Grundy (1998), Posner (1998) and Sacristán (2010). These specialists organize the knowledge according to different referents, and they are also updated according to new trends; this is because the university curriculum is subject to updating according to the needs of the social contexts in which it operates. Among the main findings, it is highlighted that the understanding of each curricular approach provides insights into the new curriculum proposals. These proposals are more related to the challenges posed by society and are necessary to move towards comprehensive professional profiles and real work opportunities. In addition, the study highlights that the new university study plans must contain the vision of the physical, social and socio-affective aspects with high levels of quality, equity, use of technologies, and a clear approach of the disciplines that promote the active participation of students, academics, employers and others advancing interdisciplinary and transdisciplinary curricular proposals. The main implication of the research is to provide scholars and researchers with a reference based on criteria of historical and current selection of curricular approaches that can be consulted in future studies on the quality of university professional training.

Keywords: Higher education; study plans; decision making; curricular approaches; interdisciplinary work.

Resumo: O objetivo deste artigo é oferecer as entidades responsáveis pelo currículo das instituições de ensino superior, a concepção do currículo universitário, as referências curriculares a serem consideradas na tomada de decisão necessária à implementação reflexiva dos planos de estudo, e os desafios do ensino superior diante das demandas da sociedade atual. $O$ fato de ser uma tarefa que envolve contribuições da teoria curricular e da disciplina própria ao objeto de estudo, que aborda um determinado currículo, o conteúdo torna-se uma ferramenta que promove, a partir do campo teórico, um dinâmico trabalho transdisciplinar e interdisciplinar, que poderia contribuir para a utilização de abordagens curriculares que apoiem a prática consciente e renovada do ensino superior. $\mathrm{O}$ estudo apresenta as contribuições e classificação de 22 abordagens curriculares de especialistas como Eisner e Wallance (1974), Molina (1997), Grundy (1998), Posner (1998) e Sacristán (2010), que organizam o conhecimento de acordo com os diferentes referentes e, além disso, se atualizam de acordo com as novas tendências, pois o currículo universitário está sujeito à renovação de acordo com as necessidades dos contextos sociais em que atua. Entre os principais resultados, destaca-se que a compreensão de cada enfoque curricular ilumina as novas propostas curriculares que estão mais 
relacionadas aos desafios colocados pela sociedade e que são necessárias para avançar em direção a perfis profissionais integrais e oportunidades reais de trabalho. Além disso, o estudo enfatiza que os novos planos de estudo universitário devem conter a visão do físico, social e socioafetivo com altos níveis de qualidade, equidade, uso de tecnologias, uma abordagem clara das disciplinas que promovem a participação ativa das pessoas universitárias, acadêmicas, empregadores e outros, que promovam propostas curriculares interdisciplinares e transdisciplinares. A principal implicação da investigação é fornecer à equipe acadêmica e de pesquisa uma referência baseada em critérios de seleção histórica e atual de abordagens curriculares que possam ser consultadas em estudos futuros sobre a qualidade da formação profissional universitária.

Palavras-chave: Ensino superior; abordagens curriculares; planos de estudo; tomada de decisão; trabalho interdisciplinar.

\section{Introducción}

El acercamiento a la toma de decisiones de carácter curricular de las instituciones de educación superior resulta estratégico para la formulación de planes de estudio en pregrados, grados y posgrados, en el tanto que orienta acerca de las diferentes teorías y enfoques curriculares que se pueden utilizar, según el propósito educativo que se formule y el perfil de salida profesional que se proyecte obtener.

Al respecto, muchas instituciones de educación superior han estado buscando respuestas concretas sobre el cómo formar a las futuras personas profesionales con perfiles tales que les provean las herramientas necesarias para transformar y responder de manera eficiente ante las demandas de la sociedad actual.

En este marco, la vasta experiencia, tanto en el plano prescrito, como el práctico y teórico de la planificación curricular de este nivel, permite generar un referente que apoye a las instituciones de educación superior en la reflexión y análisis sobre la fundamentación orientadora de sus planes de estudio. Es, ante todo, un acto de conciencia que se deriva de las labores realizadas en este campo, las cuales han permitido visualizar las formas frecuentes y habituales en las que las universidades afrontan la sistematización e implementación de planes de estudio de educación superior (PEES).

El obejtivo de este artículo está orientado a ofrecer, a los entes gestores del currículo de instituciones de educación superior, la concepción de currículo universitario, los referentes curriculares por considerar en la toma de decisiones requeridas para la implementación reflexiva de los planes de estudio, los retos de la educación superior ante las demandas de la sociedad actual y a brindar diferentes puntos de vista según el enfoque curricular, así como sus implicaciones en la posible formulación e implementación de los PEES. Lo esencial es comprender que no existe una sola forma de construcción y creación y que, por supuesto, esta puede estar sujeta a una gran cantidad de enfoques y teorías, según sea el interés con que se 
doi: http://dx.doi.org/10.15359/ree.23-3.7

URL: http://www.una.ac.cr/educare

CORREO: educare@una.cr

quieran plantear los diseños de los PEES. Así, existen tantas formas de hacerlo como enfoques, contextos y objetos de estudio; por ende, la capacidad de creación es ilimitada, pero puede fortalecerse cuando interviene tanto la participación individual como la colectiva.

El diseño curricular es un proceso que deben efectuar las instituciones de educación superior con cierta frecuencia, a fin de ampliar o actualizar su oferta educativa. El resultado del diseño curricular es el documento donde se explicitan la organización, operación y evaluación integral de la formación propuesta, esto es: el currículo.

LOS PEES se originan de estructuras que responden, directamente, a marcos normativos institucionales y políticas curriculares definidas, pero quizás, no siempre, de un acto reflexivo sobre la visión, el tiempo y el contexto. Al respecto, Julia (2011, citado en Juliao, 2014) señala que este proceso inicial debe ser entendido de la siguiente manera:

Como una reflexión crítica que busca la transformación de las prácticas, así como de las comprensiones teóricas y de los valores de las personas que intervienen en el proceso, y de las estructuras sociales e instituciones que definen su marco de actuación como actores de un proceso social y educativo. (p. 38)

Este artículo se organiza en tres apartados: el primero presenta la concepción del currículo en el marco general de la educación superior; un segundo corresponde a los referentes curriculares, sus características y componentes con sus respectivas funciones, de acuerdo con el rol que se les asigna, dentro de cada enfoque. Por último, el tercer punto describe elementos del currículo necesario en la educación superior, según las demandas y retos de la sociedad actual.

\section{El currículo en la educación superior}

La sociedad es dinámica, cambiante y activa, lo cual desafía a la educación superior (ES), a pensar y repensar las formas en que se asume la formación de los futuros profesionales. Es dinámica, en tanto no existe una única percepción y reacción ante las situaciones del entorno; además, tiene la capacidad de transformar la educación en diversos espacios. Es cambiante, porque todo evoluciona: las personas, el medio ambiente, las tecnologías, la cultura, las normas, la comunicación, las necesidades; en fin, no es posible hablar de un producto acabado. Por consiguiente, es activa, pues está en constante movimiento: los eventos del pasado influyen sobre el presente y este sobre futuros escenarios; en este sentido, los procesos de ES deben estar en permanente revisión para incorporar las nuevas tendencias que respondan de manera efectiva a necesidades sociales.

De este modo, la sociedad nos plantea el reto de identificar y comprender lo que es relevante para la enseñanza y aprendizaje en nuestras universidades, entendiendo estas como entes vivos y orgánicos que ejercen influencia sobre su evolución y desarrollo. 
En este orden de ideas, para este escrito, se define el currículo universitario como la concreción de planes de estudio dinámicos en el plano prescrito; sin embargo, cabe indicar que no es un producto acabado, sino en constante revisión de su práctica y reflexión de esta, para la formación de profesionales que inciden y transforman la sociedad.

La planificación curricular en la educación superior supone, entonces, el análisis y la valoración de la oferta curricular existente, es decir, incorporar métodos para la selección, organización, puesta en práctica y evaluación de los contenidos curriculares para realizar ajustes sustantivos. De tal suerte que los planteamientos curriculares resulten pertinentes en la formación de profesionales que respondan, de manera oportuna, a los retos y tendencias actuales de desarrollo.

Para abordar de manera integral esta conceptualización del currículo universitario, es pertinente indicar que su concreción corresponde al nivel meso, es decir, es el conjunto de decisiones sustentadas y articuladas curricularmente, por parte de los entes responsables en la formulación de programas o planes de estudio adecuados a un contexto específico. Para comprender esto de mejor manera, se puede observar la Figura 1 "Niveles de concreción curricular", donde se aprecian los tres niveles: el macro, meso y el micro.

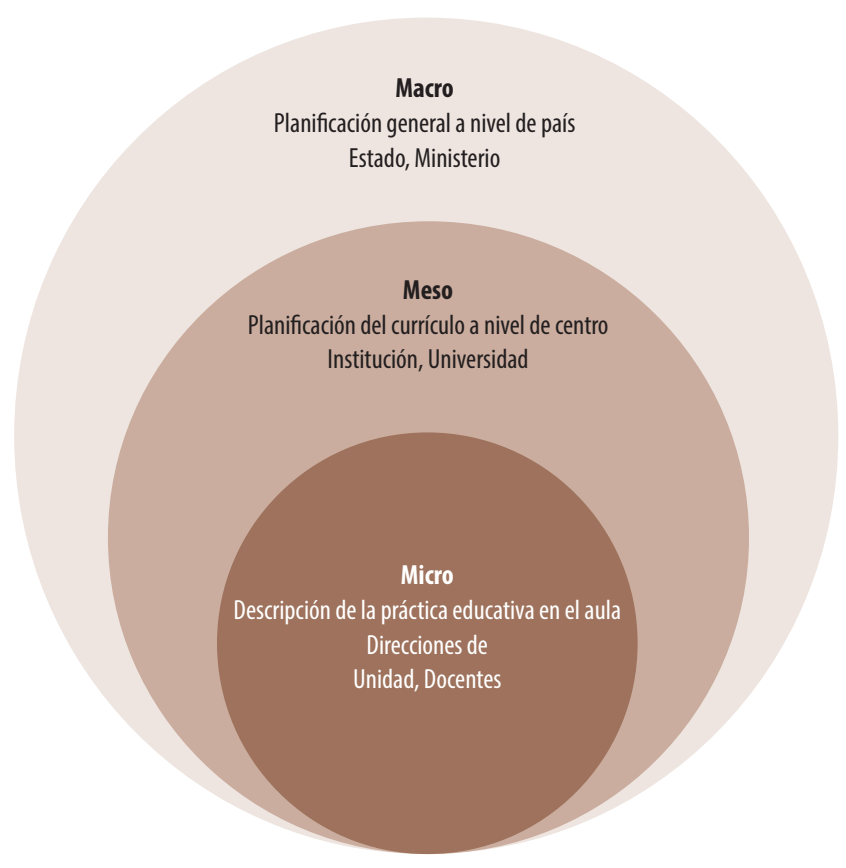

Figura 1: Niveles de concreción del currículo. Nota: Elaboración propia. 
doi: http://dx.doi.org/10.15359/ree.23-3.7

URL: http://www.una.ac.cr/educare

CORREO: educare@una.cr

Los niveles macro y micro pueden influenciar el meso, pero no es en ellos donde se concretan los planes de estudio de las universidades. Esto, debido a que como menciona Ornelas (2008), la ES se rige por su autonomía universitaria, al ser independiente del Estado o los gobiernos de turno en su gestión, mientras que a nivel micro solo se ejecuta lo formulado en los niveles anteriores.

Se entiende, entonces, que la educación superior permea, impacta y transforma, desde su ámbito académico (investigación, extensión y producción) la estructura social de la cual es parte y, por lo tanto, su valor y naturaleza académica trascienden a los niveles macro y micro.

Por prescrito, se comprende la propuesta materializada del plan con sus fundamentos, naturaleza, saberes, cursos, metodologías, perfiles, recursos y todos los elementos curriculares que esto conlleva; y el plano praxeológico en el tanto la creación de los PEES requiere del ejercicio constante de reflexionar-formular-volver a reflexionar-repensar de manera consciente, es decir, "partir de un trabajo reflexivo sobre las prácticas [(que comprende las fases del] ver - juzgar actuar - devolver [creativamente)]" (Juliao, 2014, p. 86), para lograr un producto pertinente.

\section{Referentes curriculares}

El conocimiento general, y más aún el análisis comparativo de los enfoques, concepciones y orientaciones curriculares, permite tener una visión integral del proceso curricular con el fin de orientarlo hacia metas claramente definidas. Cada universidad adopta un enfoque curricular que hila el proceso educativo y orienta el desarrollo curricular. Sin embargo, se debe recordar que la adopción de un enfoque no es excluyente de otros, se trata de realizar la combinación o combinaciones que resulten más oportunas para el cumplimiento de las metas de formación.

No existe la intención de plasmar aquí corrientes modernas, por ejemplo, las que están directamente relacionadas con el desarrollo y adquisición de competencias, atributos o resultados de aprendizaje. Se resalta, mas bien, la pertinencia que se deriva de la tradición curricular y la experiencia acumulada, de la puesta en práctica de enfoques curriculares que durante años han demostrado su vigencia para afrontar la gestión curricular en diferentes niveles y contextos.

La implementación o puesta en practica del currículo en la educación superior requiere de procesos sistemáticos de programación, organización y coordinación del plan de estudios; dichos procesos permiten concretar, de manera directa, las acciones estratégicas que se lideran desde los ámbitos académico y administrativo. Supone, además, la optimización de los recursos y la creación de las condiciones que se consideran óptimas para su desarrollo.

La siguiente revisión permite tomar decisiones sobre las formas en las que los PEES requieren ser abordados para su gestión. Se esbozan cuatro clasificaciones de enfoques curriculares que sirven como referente, reconocidas en la tradición curricular. 
Según Grundy (1998), los enfoques curriculares se clasifican en cuatro tipos: técnico, práctico, transición y crítico social. Explica el autor que poseen elementos que los caracterizan, los cuales, para efectos de este escrito, se resumen a continuación.

\section{Enfoque curricular técnico}

Se fundamenta en la construcción de planes de estudios o programas previamente establecidos con el fin de ejecutarse por parte del profesorado. Este se caracteriza por:

- Está orientado al producto.

- El profesorado es considerado como el responsable de conseguir los resultados esperados.

- Tiene un interés por el control educativo según las expectativas de lo planteado en el desarrollo curricular.

- Tiene un programa general donde se ordenan las unidades, cursos y programas.

\section{Enfoque curricular práctico}

A diferencia del enfoque técnico, aquí se considera el desarrollo del currículo desde una base cualitativa: como menciona Cazares (s. f.), la explicación y el diálogo emergen de cada actividad de aprendizaje. Se enfoca en el proceso de enseñanza-aprendizaje y no por el producto; el aprendizaje es el fruto de la interacción entre los diferentes sujetos participantes. Este se caracteriza por:

- El papel docente tiene como núcleo principal la construcción del significado del estudiantado como sujeto activo de dicho proceso.

- Las relaciones docente-estudiante se generan en un clima de igualdad y comprensión afectiva.

- Según Elliot (citado por Luna y López, 2011), el desarrollo "de una acción o tarea no puede trasgredir los principios y valores que presiden la intencionalidad educativa. [AI respecto explica] que los medios no pueden considerarse independientes de los fines, ni los fines tampoco justifica los medios" (p. 68).

- Considera el currículo como un espacio de interacción humana y ética en los procesos que se viven en las aulas.

- El profesorado aprende y mejora su práctica a través de la reflexión de esta, para que dicha actividad le permita saber afrontar situaciones difíciles. 
doi: http://dx.doi.org/10.15359/ree.23-3.7

URL: http://www.una.ac.cr/educare

CORREO: educare@una.cr

- La investigación-acción es el medio por el que el profesorado elabora sus propias soluciones, en relación con los problemas prácticos a los que se enfrentan continuamente.

- Según Elliot (citado por Luna y López, 2011), “Los problemas educativos y curriculares son prácticos y por ende no pueden ser tratados de la misma manera como si fueran teóricos" (p. 69).

\section{Enfoque curricular de transición}

Se basa en el modelo de núcleos temáticos y problémicos, que concibe el currículo como un puente entre la teoría, la realidad y la práctica. Su objeto es facilitar el conocimiento de las acciones educativas. Como lo explican Luna y López (2011):

Se asume su concepción como proyecto educativo, como proceso en construcción y como campo de investigación, donde cada proyecto surge de las necesidades de un contexto social y educativo concreto, y ... se sustenta en la consideración del currículo como proceso de investigación. (p. 69)

El enfoque, según Luna y López (2011, pp. 69-70) se caracteriza por:

- No se formula un tipo específico de estrategias metodológicas; se establecen en un trabajo conjunto con los profesores y según el contenido a desarrollar. ...

- Respeto por las diferencias entre los actores: ... docentes y estudiantes, sin la pretensión de decidir o fijar posiciones sobre un tema en especial; se pretende reconocer, ... las estructuras cognitivas, antes que alcanzar una verdad y propiciar la construcción de conocimientos....

- El método que interviene en este enfoque es el investigativo cualitativo....

- El docente debe realizar una actividad reflexiva en una toma de conciencia entre los estudiantes ante la sociedad y ante el mismo proceso de enseñanza, que se convierte en una praxis real y concreta dentro del aula....

- [El docente] es uno de los pilares de este enfoque, no sólo por ser el responsable de la ejecución curricular, sino porque le permite elevar a otra dimensión su quehacer educativo, en la medida en que le otorga el papel investigador a través del currículo, desde el cual se impulsa la cualificación profesional y el desarrollo personal.

- El docente se caracteriza por la idoneidad específica en el aula, por su apego y dominio de la materia, por su capacidad de manejo de grupos, por unas relaciones satisfactorias 
entre estudiantes, por la evaluación subjetiva de ellos, y por su preocupación por la capacitación en la práctica docente.

- [El docente posee] una permanente actitud autocrítica sometida al debate público. Contextualizada su labor en la institución en la comunidad y en la sociedad, participa en actividades crítico-reflexivas sobre sus problemas educativos, se ocupa de mantener la unidad dialéctica teórica práctica, se compromete a una teoría curricular específica, y a partir de ella, define toda su acción, incluyendo la evaluación tanto de su práctica, como la de los estudiantes y desde luego de la misma teoría....

- [El] estudiante ... se caracteriza por ser: curioso, crítico, reflexivo, inconforme y de gran sensibilidad ante el conocimiento que recibe por parte del docente.

\section{Enfoque curricular crítico social}

El enfoque curricular critico-social guarda un fuerte vínculo con el enfoque práctico. Como lo define Elliot en Luna y López (2011): "considera al docente como el único investigador de su propia práctica, siguiendo la investigación-acción como planteamiento alternativo en la mejora del proceso educativo" (p. 70); y tanto docentes como estudiantes aprenden de su propia realidad. Este se caracteriza por:

- El currículo está dirigido a la construcción conjunta entre docentes y estudiantes a través de la praxis, buscando la transformación.

- La acción y la reflexión, la teoría y la práctica se unifican en un proceso dialéctico.

- La fuente para la selección de los contenidos es la propia realidad social dentro de la cual se enmarca la escuela.

- Según Freire en Luna y López (2011): "la acción crítica es la praxis, que se mueve entre la reflexión y la acción". (p. 70)

- La enseñanza es un proceso continuo de toma de decisiones, el cual se establece entre docente-estudiante desde el principio de la experiencia, deja de ser esta una relación de autoridad.

- Tienen un interés emancipador, el currículo no consiste en un conjunto de planes a desarrollar, sino, como aclaran Herrera, Montes, Santiago y Tapia (2017), como aquel proceso de interacciones donde la planificación, la acción y la evaluación están relacionadas e integradas en un proceso de investigación-acción, esta es la oportunidad de avanzar hacia la transformación del proceso de enseñanza-aprendizaje, mediante la crítica que permite el método dialéctico. 
doi: http://dx.doi.org/10.15359/ree.23-3.7

URL: http://www.una.ac.cr/educare

CORREO: educare@una.cr

- La colaboración de docentes, familias, estudiantes y personal investigador en el proceso de transformación y reflexión, donde no se presentan relaciones jerárquicas, y predomina la cooperación, la autonomía individual o colectiva de pensamiento y acción.

De acuerdo con Eisner y Wallance (s. f., mencionados por Pardo, 2013), se propone una clasificación en cinco enfoques: el desarrollo del proceso cognoscitivo, el de relevancia de la reconstrucción social, el tecnológico, el de autorrealización o experiencia consumatoria y el racionalismo académico, que se resumen a continuación.

\section{Enfoque curricular de desarrollo del proceso cognoscitivo}

En este enfoque, la educación se visualiza como un mecanismo que asegura el perfeccionamiento de destrezas intelectuales como herramientas para adaptarse o para dar forma a nuevas situaciones, se presume que dichas destrezas se transfieren a una amplia variedad de situaciones fuera de la escuela como expresión normal de aprendizaje. Es transferir el conocimiento dado por otras personas a través del estímulo-respuesta. Se caracteriza por:

- No se compromete con contenido determinado alguno, es "neutral" respecto a las metas educacionales. Se preocupa por la parte procedimental del binomio enseñanzaaprendizaje antes que por la finalidad o los contenidos.

- Enfatiza en la forma de acceder al conocimiento a través de herramientas intelectuales.

- Se ocupa del desenvolvimiento oportuno y orgánico de los procesos intelectuales y en el afinamiento de una gama de destrezas cognoscitivas, que pueden ser practicadas en cualquier realidad o situación problemática.

- Alude al perfeccionamiento de las operaciones intelectuales, se enfoca en el "cómo" (procesos estructurales) y no en el "qué" (contenidos culturales).

- Concibe al estudiantado como un elemento interactivo y adaptativo en un sistema, al que se le proporcionan todos los procedimientos intelectuales correctos y necesarios dentro del proceso.

- Enmarca su enfoque en el estudiantado. Aspira a capacitarlo de una gran autonomía intelectual, que le permita hacer su propia selección e interpretación respecto de las situaciones significativas que se encuentran más allá del contexto de la instrucción.

- Considera el proceso de aprendizaje en sí mismo más que en el contexto social amplio en que este ocurre. 


\section{Enfoque curricular de relevancia de la reconstrucción social}

Velasco (2014) indica que este enfoque ha permanecido en vigor en gran parte de la historia de las reformas educacionales y que "manifiesta un vigoroso énfasis en el papel de la educación y del contenido curricular dentro de un contexto social más amplio, poniendo de relieve las necesidades sociales por sobre las necesidades individuales". Agrega que "se ubican en un primer plano tanto la reforma social en aplicación como la responsabilidad por el futuro de la sociedad misma en desarrollo" (p. 46). De acuerdo con Velasco (2014), este enfoque se caracteriza por:

- Considerar "su relación con las <metas sociales > y el desarrollo actual, ... en donde los valores sociales así como las posiciones políticas se dan como <categorías conocidas. ... (p. 46)

- La escuela asume el rol de ser puente entre lo que es y lo que debería ser. Es el elemento intermedio a través del cual la sociedad puede cambiarse a sí misma y proyectarse dinámicamente.

- Se observan dos posiciones: "una, centrada en el presente y, en consecuencia, adaptativa, ... otra; centrada en el futuro y, por consiguiente, reformista"(p.47). Según Velasco (2014), el punto"común entre [ambas es] la consideración del currículum como el medio a través del cual los estudiantes aprenden a vincularse con las metas sociales de su comunidad [y enfrentar estos asuntos] para emprender su consecución efectiva en el tiempo, ... mantenerse y funcionar con eficiencia en un mundo de rápido cambio. (p. 47)

- Enfatiza en las necesidades colectivas antes que en las necesidades individuales.

\section{Enfoque curricular tecnológico}

Este enfoque centra su atención en el proceso, específicamente en el cómo, más que en el qué, de la educación. La función del currículo consiste en la búsqueda y el uso de los medios para conseguir ciertos fines preestablecidos. Según Velasco (2014), constituye "un 'proceso tecnológico' [donde] los instrumentos adecuados llevan a la gestación de un sistema educacional con la aplicación de un modelo industrial, a través de una óptima organización del material seleccionado".

Este se caracteriza como un "proceso tecnológico ... donde los instrumentos adecuados ... llevan a la gestación de un sistema educacional con la aplicación de un modelo industrial, a través de una óptima organización del material seleccionadoacteriza [por]: 
doi: http://dx.doi.org/10.15359/ree.23-3.7

URL: http://www.una.ac.cr/educare

CORREO: educare@una.cr

- Su atención se fija"propiamente en la tecnología, por la cual el contenido es comunicado y con la cual el aprendizaje se facilita, haciendo escasa o ninguna referencia al contenido" y "el proceso mismo de conocer y aprender".

- "Se traduce en un desarrollo de la tecnología de la enseñanza o para la instrucción".

- Emplea "el lenguaje de la producción, ... [similar al utilizado] en los sistemas industriales y contables, y en el análisis de sistema. Su lenguaje intenta ser tan eficiente como el sistema que, pretende aplicar: preciso, breve, secuencialmente lógico, directo y práctico.

- El sujeto que aprende no es considerado como un elemento problemático y dinámico del sistema en uso, sino como "una constante".

- La función del docente consiste ... en atender la organización del material anticipadamente al momento [en] que [la persona aprendiz llega] a la sala de clase, siguiendo las etapas previstas del aprendizaje. ... Se traduce ... en saber organizar los materiales con anterioridad a la clase, [realizar su distribución adecuadamente y controlar] su acción.

- El [currículo] constituye el proceso tecnológico que busca, analiza y provee los medios eficientes y dinámicos para alcanzar los fines deseados. (p. 49)

\section{Enfoque curricular autorrealización o experiencia consumatoria}

Velasco (2014) concibe lo siguiente:

La vigencia de un 'proyecto de vida personal'y la expectativa de una realización personal auténtica y libremente responsable. [Sobre todo], está centrado en el [estudiante] y destinado a su autonomía y crecimiento vital, considerándose a la educación como un proceso capacitador armónico que posibilita los medios para la liberación y el desarrollo de cada sujeto. (p. 44)

El enfoque, según Velasco (2014), se caracteriza por:

- La organización de experiencias personales integradoras y satisfactorias para cada aprendizaje individual, [como] oportunidades vitales, profundas y trascendentes, que actúan como una fuerza liberadora de la personalidad del educando.

- Tomando como punto central ... el quién (sujeto...), procura atender ... tanto el qué como el cómo ... se preocupa ... lo qué se enseña ... al considerar la instrucción como ... una experiencia vital y potencialmente enriquecedora en sí, ... [abarcando la importancia del] contenid... pero también ... el proceso educativo en sí mismo. ... 
- Propugna el que los objetivos de la educación se definan en términos de un proceso personal emergente, activo, confluente y expresivo....

- Junto con enfatizar el crecimiento personal y el currículum como experiencia integradora ... (cabal, completa, consumatoria), considera la posibilidad del cambio, en virtud de que la dinámica de la integración y autonomía personal está implícitamente expuesta a la acción de factores adversos provenientes del ambiente social (posición reformista)....

- El profesor ... [es] un artífice que guía al [estudiante ...] a descubrir cosas por sí mismo, ... estimula la iniciativa y creatividad ... y ... sugiere diversas oportunidades y formas de aprendizaje personalizado.

- Las necesidades individuales priman sobre las necesidades sociales. (pp. 44-45)

\section{Enfoque curricular racionalismo académico}

Para Castro (2010, Enfoque curricular académico, párr. 1-2):

Es una de las formas racionalistas de ver el currículo, ... intenta darle prioridad a la razón antes que a la experiencia o a la realidad, ... se hermana con el dogmatismo y el idealismo y tiene absoluta confianza en la razón. ... El propósito es capacitar para adquirir las herramientas que permitan participar en la tradición cultural y proveer su acceso a las grandes ideas y creaciones humanas.

Castro (2010) lo caracteriza:

- La función de la institución educativa es la transmisión cultural: cultivar el intelecto (Enfoque curriculr académico, párr. 2).

- Se centra en proporcionar al estudiante acceso a las grandes ideas del conocimiento.

- Se basa en las disciplinas creadas para la transmisión cultural.

Sacristán (2010), por su parte, clasifica en cuatro grupos los enfoques curriculares a saber, la suma de exigencias académica, la base de experiencias, el legado tecnológico y el configurador de la práctica. Se sintetizan como sigue:

\section{Enfoque curricular suma de exigencias académicas}

Es un enfoque centrado en los contenidos programáticos y elaborados desde la formalización de las diferentes asignaturas. 
doi: http://dx.doi.org/10.15359/ree.23-3.7

URL: http://www.una.ac.cr/educare

CORREO: educare@una.cr

- Organiza el conocimiento por áreas de formación y componentes de formación.

- Los planes de estudio distribuyen el conocimiento en espacios académicos especializados en donde se yuxtaponen los saberes disciplinarios de una manera secuencial, desde el primero hasta el último semestre.

\section{Enfoque curricular base de experiencias}

Se preocupa por la experiencia e interés del estudiantado. Este enfoque curricular aparece como reacción al enfoque academicista y busca que el estudiantado tenga la experiencia directa de la elaboración del conocimiento; por eso el método se constituye como en la herramienta integral del descubrimiento y la construcción del conocimiento.

- Es el modelo activo cuya esencia consiste en construir el conocimiento a través de la experiencia particular hasta llegar a lo general.

- Combina las exigencias académicas con el currículo como base de experiencias, pero este último entendido no como un descubrimiento del conocimiento, sino como una aplicación de los conocimientos teóricos en la resolución de estudios de caso o en la solución de planteamientos problémicos del conocimiento.

- Se implementa de los créditos académicos, en los planes de estudios con asignaturas que complementan hora teórica con hora práctica; combina el discurso con la praxis.

- Aplica el conocimiento en la solución de las necesidades del alumnado, los problemas sociales más significativos, el trabajo colaborativo de estudiantes y docentes y la interdisciplinariedad.

\section{Enfoque curricular legado tecnológico y eficientista}

Este es un enfoque dirigido a atender las numerosas demandas sociales para responder al mundo laboral y empresarial antes que el campo investigativo de generación de conocimiento. Estas modalidades se crean con el claro concepto de educación técnica, profesional y tecnológica.

- Esta formación está orientada a suplir necesidades en el corto plazo.

- Retoma al mundo tecnológico entendido como una reflexión de la técnica y no como una aplicación de las ciencias puras.

- Este enfoque no aporta elementos para elevar la cultura de una sociedad. 
Desde lo que define Eraso (2008):

Este enfoque curricular responde más a la gestión científica del aparato industrial y empresarial antes que a la gestión investigativa, dejando de lado los fundamentos psicológicos, antropológicos, filosóficos y sociológicos para dar paso a una estructuración de corte administrativo, en donde la planeación, organización, ejecución y control del conocimiento racionalizan la gestión científica investigativa. (p.40)

\section{Enfoque curricular configurador de práctica}

Este enfoque considera que las teorías curriculares también son sociales, por cuanto las personas se forman no solo por el campo laboral, sino que se preparan también para la transformación social en un lugar, en un tiempo y en unas circunstancias propias de cada sociedad.

- En esta medida, no solo el modelo teórico-práctico se preocupa por llevarlo únicamente en el plano del conocimiento, sino que hace referencia a la sociedad, la cultura y a la naturaleza para responder a la igualdad de oportunidades a las cuales tienen derecho toda la ciudadanía del mundo.

Según Posner (1998), los enfoques curriculares se clasifican en cinco grupos: el tradicional, el experiencial, la estructura de disciplinas, el cognitivo y el conductista, los cuales se describen a continuación.

\section{Enfoque curricular tradicional}

Este enfoque tiene como propósito transmitir la herencia cultural y científica, es decir, que la investigación que innova y crea conocimiento pasa a un segundo plano. Este enfoque se caracteriza por:

- Un enfoque sobre un solo tema de estudio.

- Enseñanza centrada en el personal docente, quien emplea métodos de conferencia y recitación en escenarios de grupos completos.

- Materiales que hacen énfasis en libros de texto y guías de trabajo.

- Evaluación regular mediante pruebas escritas.

- Énfasis en las notas. 
doi: http://dx.doi.org/10.15359/ree.23-3.7

URL: http://www.una.ac.cr/educare

CORREO: educare@una.cr

\section{Enfoque curricular experiencial}

Está basado en el supuesto de que todo lo que les suceda a sus estudiantes ejerce influencia sobre sus vidas y, por consiguiente, el currículo debe ser considerado en forma extrema amplia, no solo en términos de lo que puede planearse para los grupos de estudiantes en los salones de clase y aún fuera de ellos, sino también en términos de todas las consecuencias no anticipadas de cada situación nueva que los individuos enfrentan.

El enfoque busca el desarrollo individual continuo en áreas como la planeación, uso de recursos en la labor, solución de conflictos, creación de pensamiento y responsabilidad. Se caracteriza porque:

- Depende más de la comunidad, considerada como un recurso, que de los libros de texto y de otros materiales de enseñanza fabricados.

- Los salones de clase deben estar centrados en el estudiantado, con énfasis en el trabajo estudiantil en pequeños grupos cooperativos y no tanto en el trabajo competitivo a nivel del grupo entero.

- Está organizado alrededor de labores permanentes, por ejemplo, proyectos que demandan tiempos relativamente largos para terminar.

- Depende de un profesor o profesora, quien coordina y es un recurso antes que una persona que tiene el control.

- Emplea métodos de evaluación dirigidos a la demostración de competencias en las labores del mundo real; más que en pruebas escritas que hacen énfasis en la retención de hechos y en terminología.

\section{Enfoque curricular estructura de las disciplinas}

Este enfoque curricular organiza las áreas de formación y sus componentes a partir de los conceptos básicos o fundamentales de las disciplinas y, en consecuencia, el estudiantado deriva el resto de conocimiento de estas a partir de sus conceptos.

Tiene como propósito fundamental el desarrollo del intelecto humano; en consecuencia, las disciplinas del conocimiento constituyen el contenido más apropiado para este fin, por cuanto la obtención del conocimiento conlleva una metodología en su proceso de descubrimiento, innovación y aplicación. Se caracteriza por lo siguiente:

- Cada disciplina tiene su propia forma de realizar investigación, de modo que no existe un solo método investigativo, sino varios, de acuerdo con el estatuto epistemológico de cada una. En esta medida, el proyecto de aula, el trabajo dirigido, el proyecto socio jurídico o el taller creativo se constituyen en unos medios de investigación formativa que se utilizan en el tiempo independiente en las instituciones de educación superior. 
- Está confinado a una sola disciplina dentro de una materia individual.

- Se concentra en un pequeño conjunto de temas conceptuales fundamentales; requiere el uso de material de fuente primaria y de manipulación.

- Utiliza pruebas escritas con énfasis en la solución de problemas.

- Requiere un profesorado que modele la investigación en la disciplina, no tanto que actúe como una fuente de información.

\section{Enfoque curricular conductista}

Este enfoque no se centra en el contenido sino en que el estudiantado sea capaz de aprender nuevos comportamientos como consecuencia de la enseñanza. Se basa en un sistema de recompensas para el comportamiento apropiado y el desempeño exitoso.

Se enfatiza en los contenidos y la formulación de objetivos, razón por la cual tuvo mucha trascendencia la taxonomía o clasificación de Benjamín Bloom. Hoy estos objetivos han pasado a convertirse en logros y estos últimos se han transformado en competencias.

El propósito de este enfoque es alcanzar destrezas, habilidades, competencias y procesos: así, entonces, el contenido del currículo comprende un conjunto de destrezas descritas por enunciados que especifican comportamientos observables y medibles, denominados objetivos conductistas o de desempeño. Se caracteriza por:

- Objetivos diversos de desempeño estrechamente alineados con los métodos de evaluación.

- Métodos controlados por el profesorado que utilizan la enseñanza explicita de habilidades con amplias oportunidades para practicarlas.

- Métodos de evaluación con referencia a criterios.

\section{Enfoque curricular cognitivo}

Este enfoque se centra en la creación del pensamiento y su significado y, por lo tanto, considera el desarrollo de la mente como el propósito central de la educación. En esta medida, el modelo pedagógico conceptual contribuye a la construcción de sí mismo de especial manera, partiendo de la noción, el concepto, la categoría, el juicio y el raciocinio. Este proceso de construcción del conocimiento permite al estudiantado que, sin importar los contenidos y las disciplinas, pueda aprender de la realidad directamente por cuanto las ideas son innatas. 
doi: http://dx.doi.org/10.15359/ree.23-3.7

URL: http://www.una.ac.cr/educare

CORREO: educare@una.cr

Además de psicología, existen otras disciplinas que pertenecen a la ciencia de la cognición: la lingüística, la inteligencia artificial y la lógica. Las ciencias de la cognición pretenden hacer del comportamiento el objeto del conocimiento. Se caracteriza por:

- Trata los temas con gran profundidad.

- Enseña habilidades y conceptos solamente en el contexto de las experiencias y conocimientos previos del estudiantado.

- Se basa en la motivación intrínseca.

- Prefiere las entrevistas clínicas y la observación a las pruebas estandarizadas para la evaluación.

Soto $(2003$, citada por Molina, 2014) clasifica los enfoques curriculares en humanismo, competencias, constructivismo y problematizador:

\section{Enfoque curricular humanismo}

Este es un enfoque que se centra en el individuo, de manera que pretende proveer experiencias que satisfagan las necesidades del estudiantado para lograr su crecimiento personal y la búsqueda del desarrollo integral. Por eso, busca ofrecer al individuo vivencias que estimulen su crecimiento personal, el respeto a las diferencias individuales, el desarrollo de sus capacidades y la superación de sus limitaciones o deficiencias.

Contempla, además, los campos afectivo y cognoscitivo del futuro profesional. En primera instancia, porque los procesos de enseñanza y aprendizaje están ligados al campo emocional, es decir, involucran emociones, actitudes y valores de los estudiantes. En segunda instancia, porque la comprensión y aplicación de los conocimientos tienen como propósito ayudar en la formación de cada estudiante como persona y facilitar su aprendizaje.

El profesorado se ve como un guía de esa formación y el estudiantado como un ente activo en su contexto.

Como lo expone Villarini en Jiménez (2008):

Los objetivos y el contenido curricular se orientan a lo que es pertinente y significativo para el proceso de desarrollo del estudiante, lo que conlleva a que estos sean sumamente flexibles y experimentales. ... [De manera que], estos deben estar conectados con la realidad del estudiante. (p. 70) 


\section{Enfoque curricular competencias}

Catalana, Avolio y Sladogna en González (2006) definen que el enfoque curricular por competencias responde a los desempeños esperados de una persona en el área ocupacional, para resolver problemas propios del quehacer en su profesión. El propósito de este enfoque es contar con una oferta formativa que le permita al futuro profesional desarrollar destrezas, habilidades y actitudes requeridas en términos de pertinencia con el empleo, resolución de problemas, toma de decisiones, planificación y control de sus actividades.

El modelo, según Catalano, Avolio y Sladogna en Zúñiga (2011), se caracteriza por:

- La metodología permite elaborar una descripción integral de los desempeños y tareas esperadas de acuerdo con el propósito y elementos de competencia de la disciplina.

- Toma en cuenta los roles del perfil profesional.

- Articular las exigencias del mundo productivo con la formación profesional a desarrollar.

- Tiene una estructura modular.

- Integra capacidades de contenido, teoría y práctica, de actividades y evaluación.

- Criterios de evaluación basados en la norma.

- Adopta un enfoque de enseñanza-aprendizaje significativo.

\section{Enfoque curricular constructivismo}

Este enfoque curricular percibe el proceso de enseñanza-aprendizaje como dinámico, participativo e interactivo; el alumnado es el sujeto responsable de construir su propio aprendizaje. Según Coll et al. (1999), "esa construcción incluye la aportación activa y global del [estudiantado], su disponibilidad y conocimientos previos en el marco de una situación interactiva, en la cual el profesor actúa de guía y de mediador entre el estudiantado y la cultura" (p. 11).

El enfoque, desde Castillo en Yagual (2015), tiende a fomentar "el desarrollo de conocimientos, habilidades, actitudes y hábitos para la investigación y la innovación científica y teorológica, como base para el progreso [de la sociedad] y el mejoramiento de la calidad de vida" (p. 15).

De acuerdo con Lemme en Yagual (2015), se estimula el desarrollo de la personalidad en el estudiantado, considerando el aprender a conocer, aprender a hacer, aprender a convivir y aprender a ser. 
doi: http://dx.doi.org/10.15359/ree.23-3.7

URL: http://www.una.ac.cr/educare

CORREO: educare@una.cr

Este enfoque se caracteriza por:

- El plan de estudios promueve metodología, objetivos, actividades y evaluación donde la disciplina que se quiere formar permita en el estudiantado el auto descubrimiento, proactividad, el protagonismo del proceso de enseñanza y aprendizaje.

- Permite la interacción de las personas con su entorno en el proceso de adquirir y refinar destrezas y conocimientos.

- Asume que el estudiantado aprenda de manera significativa y permanente cuando construye en forma activa sus propios conocimientos.

- Según Molina (1997), "las experiencias y los conocimientos previos del educando facilitan o inhiben la construcción de nuevos conocimientos." (p. 29)

- Según Duarte, Roberto, Moreira y Valdés (2003) "El proceso de construcción del conocimiento se basa en la "acción sobre la realidad" realiza el sujeto que conoce" (p. 72).

- Se provee un ambiente académico en el cual se pueda experimentar la investigación espontánea.

- Según García, Edel y Escalera (2010), “El aprendizaje es un proceso social que debería suceder entre los grupos colaborativos con la interacción entre "pares" (p. 57).

- Según Molina (1997), "la acción grupal cooperativa y solidaria dinamiza los procesos de creación del conocimiento y fomenta la calidad de los aprendizajes" (p. 30).

\section{Enfoque curricular problematizador}

Este enfoque trabaja sobre problemas del conocimiento y su relación e integración con el contexto. Navas (2012) "considera la escuela como una comunidad de personas que reflexionan críticamente sobre sus valores y su propia práctica en un contexto social e histórico determinado" (p. 40). Este enfoque se caracteriza por:

- Plantear una propuesta contextualizada, negociada y pactada entre los actores del currículo.

- Los problemas del conocimiento se relacionan e integran con el contexto y otros contextos.

- Los contenidos deben ser socialmente significativos e incluyen tanto lo afectivo y lo actitudinal como lo cognitivo.

- Permite que los estudiantes vivan la tensión del conocimiento sin evitar que se reflejen las contradicciones y las situaciones problemáticas.

- En el aula de clase, se pueden presentar opiniones distintas, las cuales el alumnado debe aprender a respetar y a debatir desde la argumentación y la palabra. 
De lo expuesto hasta ahora, lo realmente importante para los PEES es la toma de decisiones sobre la gestión, es lograr discriminar y seleccionar el rol que asume cada uno de los elementos y componentes curriculares en los diferentes enfoques. Esto es, visualizar el rol docente, el del estudiantado, del contenido, del proceso y de los recursos que resulte más coherente con los principios institucionales, el plan de estudios y los requerimientos de formación desde la perspectiva social.

Como puede observarse, la información sobre los enfoques curriculares es muy diversa y tiene una función práctica, esta es guiar el proceso de formulación de PEES; sin embargo, lo que interesa es confrontarlas según sea la disciplinas o tendencias de formación profesional. Para fortalecer el tema, a modo de ejemplo, y con el propósito de facilitar la toma de deciones, en la Tabla 1 se presenta un cuadro comparativo entre algunas orientaciones o enfoques curriculares que sirven como referente del ejercicio a realizar a la hora de optar por la estrategia curricular en la que se sustentara el PEES.

Tabla 1: Comparativos enfoques curriculares

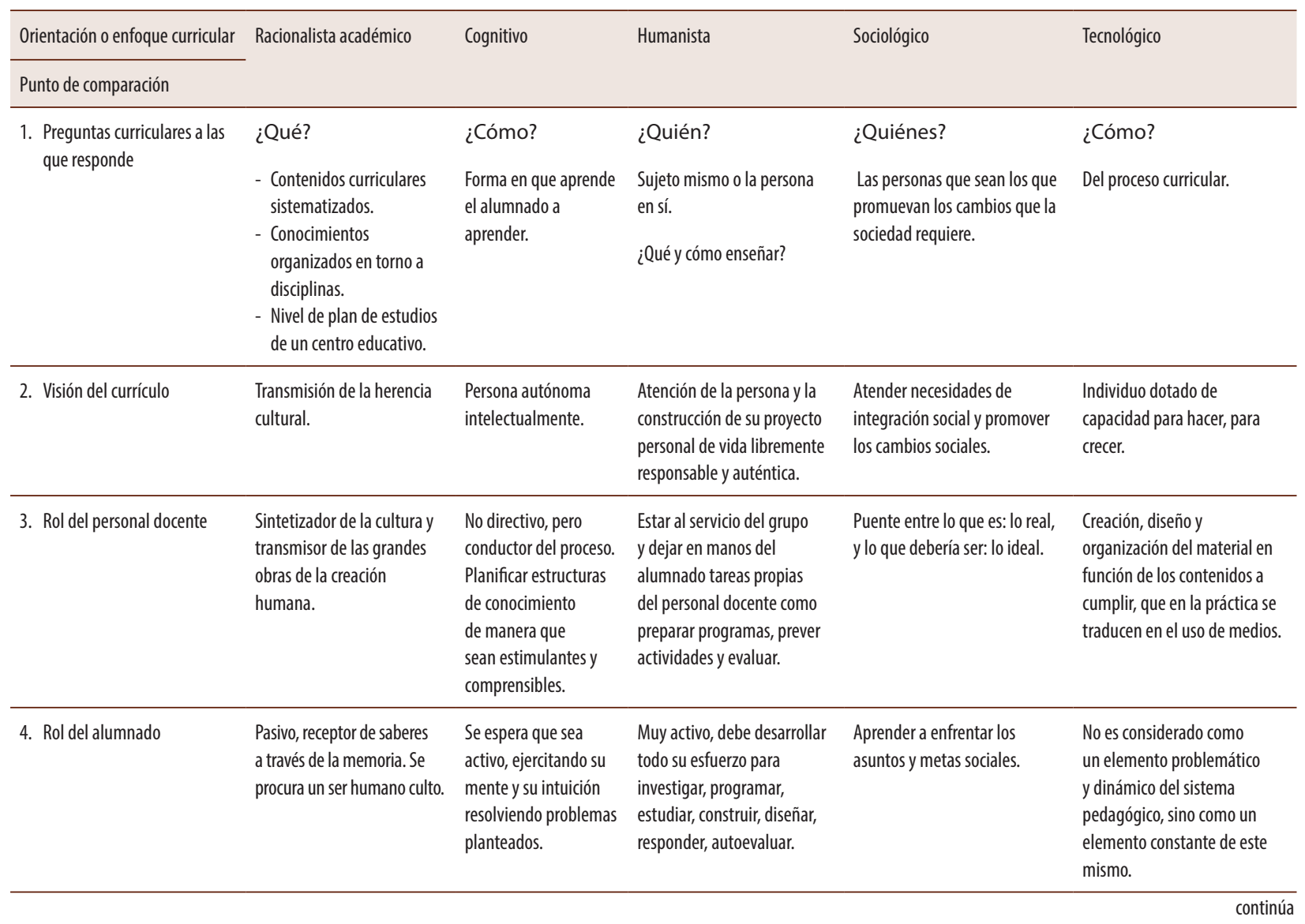


doi: http://dx.doi.org/10.15359/ree.23-3.7

URL: http://www.una.ac.cr/educare

CORREO: educare@una.cr

\begin{tabular}{|c|c|c|c|c|c|}
\hline 5. Concepto de aprendizaje & $\begin{array}{l}\text { El desarrollo cognitivo } \\
\text { centrado en el conocimiento } \\
\text { y su estructuración en la } \\
\text { mente del estudiantado. }\end{array}$ & $\begin{array}{l}\text { Orientado en un sentido } \\
\text { de crecimiento del } \\
\text { sujeto. Enmarca su } \\
\text { enfoque en el alumnado } \\
\text { y considera el proceso } \\
\text { de aprendizaje en sí } \\
\text { mismo, más que en el } \\
\text { contexto social en que } \\
\text { este ocurre. }\end{array}$ & $\begin{array}{l}\text { Considera la posibilidad } \\
\text { del cambio, en virtud } \\
\text { que la integración y } \\
\text { autonomía personal, está } \\
\text { implícitamente expuesta a la } \\
\text { acción de factores adversos } \\
\text { que provienen del ambiente. }\end{array}$ & $\begin{array}{l}\text { Busca capacitar al ser humano } \\
\text { para mantenerse y funcionar } \\
\text { con eficiencia en un mundo de } \\
\text { rápido cambio. }\end{array}$ & $\begin{array}{l}\text { Fija su atención no tanto en } \\
\text { el proceso mismo de conocer } \\
\text { y aprender sino propiamente } \\
\text { en la tecnología y su uso, } \\
\text { mediante la cual el contenido } \\
\text { es comunicado y a través del } \\
\text { cual el aprendizaje se facilita, } \\
\text { haciendo escasa o menos } \\
\text { referencia al contenido. }\end{array}$ \\
\hline 6. Influencia filosófica & Ética individualista. & $\begin{array}{l}\text { Autonomía } \\
\text { intelectualista. }\end{array}$ & Reformista. & Adaptativa y reformista. & Modelo industrial. \\
\hline $\begin{array}{l}\text { 7. Corriente psicológica en la } \\
\text { que se apoya. }\end{array}$ & Intelectualista & Desarrollista. & Humanista. & Psico-social. & \\
\hline $\begin{array}{l}\text { 8. Autores y autoras que la } \\
\text { impulsan }\end{array}$ & $\begin{array}{l}\text { Juan Federico Herbart } \\
(1776-1841)\end{array}$ & $\begin{array}{l}\text { Jerome S. Bruner, } \\
\text { Robert Gagné y Jean } \\
\text { Piaget. }\end{array}$ & $\begin{array}{l}\text { Abraham Maslow, Víctor } \\
\text { García de la Hoz, Pierre } \\
\text { Fauré, Amparo Martínez, } \\
\text { Ana M. Pabón, Silvia Álvarez, } \\
\text { Wolfgang Paul Sieggel y Carl } \\
\text { Rogers. }\end{array}$ & $\begin{array}{l}\text { Michel Scriven. } \\
\text { John Dewey. } \\
\text { Jacques Maritan. } \\
\text { Paulo Freire. }\end{array}$ & $\begin{array}{l}\text { Roger Kaufman, Robert } \\
\text { Mager, Robert Gagné, Clifton } \\
\text { Chadwick y Skiner }\end{array}$ \\
\hline 9. Ventajas & $\begin{array}{l}\text { A partir de él, la pedagogía } \\
\text { se convierte en una } \\
\text { disciplina formal. }\end{array}$ & $\begin{array}{l}\text { Hace alcances sobre } \\
\text { cómo se producen } \\
\text { y desarrollan los } \\
\text { procesos cognitivos en } \\
\text { el estudiante según su } \\
\text { etapa evolutiva. }\end{array}$ & $\begin{array}{l}\text { La posibilidad de que } \\
\text { el alumnado ejercite } \\
\text { su capacidad de tomar } \\
\text { decisiones deliberadas, } \\
\text { utilizando su inteligencia, la } \\
\text { voluntad y el razonamiento. }\end{array}$ & $\begin{array}{l}\text { Ha sido la base para las } \\
\text { innumerables reformas } \\
\text { educacionales que el } \\
\text { mundo occidental ha ido } \\
\text { experimentando. }\end{array}$ & $\begin{array}{l}\text { Conceptualiza la función del } \\
\text { currículo como la búsqueda y el } \\
\text { uso consiguiente de los medios } \\
\text { eficientes para conseguir } \\
\text { ciertos fines preestablecidos y } \\
\text { no problemáticos. }\end{array}$ \\
\hline 10 Desventajas & $\begin{array}{l}\text { El clasicismo y el } \\
\text { intelectualismo siguen } \\
\text { siendo su esencia. }\end{array}$ & $\begin{array}{l}\text { La gran dificultad } \\
\text { para identificar los } \\
\text { procesos intelectuales } \\
\text { más significativos y } \\
\text { eficientes a través de } \\
\text { los cuales ocurre el } \\
\text { aprendizaje. }\end{array}$ & $\begin{array}{l}\text { Optar por la persona no } \\
\text { es fácil, si se considera la } \\
\text { complejidad de la persona en } \\
\text { cuanto es. }\end{array}$ & $\begin{array}{l}\text { Exige que las personas según } \\
\text { (Campos, 2011)"sean mejor } \\
\text { capacitadas para encarar los } \\
\text { cambios, a la vez que establece } \\
\text { que deben ser educadas para } \\
\text { intervenir activamente en } \\
\text { orientar el cambio, en promoverlo } \\
\text { constructivamente" (p. 9). }\end{array}$ & $\begin{array}{l}\text { No considera la individualidad } \\
\text { del que aprende ni el } \\
\text { contenido cultural que define } \\
\text { la experiencia curricular. }\end{array}$ \\
\hline
\end{tabular}

Nota: Elaboración propia con referentes de Castillo (2003) y Campos (2011).

\section{El currículo necesario en la educación superior y las demandas de la sociedad actual}

La educación superior contribuye a la formación de profesionales con una visión integral desde lo físico, social y socioafectivo. Es un proceso integral, planificado para dar una respuesta pertinente a las demandas de la sociedad en la formación de la persona, dentro de un perfil determinado, que se concreta visiblemente a través del currículo.

Las expectativas, demandas y retos que se plantean en la educación superior han ido variando de acuerdo con los retos de la sociedad actual. Vivimos en un contexto de cambio rápido y constante, al respecto se plantean algunas perspectivas fundamentales: 
1. Es necesario un planteamiento de alta calidad, que tome en cuenta la inclusión social y el respeto a la diversidad en todas sus acepciones, una propuesta educativa pertinente, que brinde las oportunidades de acceso para la igualdad de oportunidades y la posibilidad de transformar de manera permanente y dinámica su razón de ser.

2. La educación superior debe fijar su misión en el desarrollo de una propuesta educativa que equipe al futuro profesional, con las herramientas para hacer frente a los retos de la sociedad globalizada y de la información, de tal suerte que logre integrarse a esta como persona y realizar su contribución para el bienestar común. En este orden de ideas, esas herramientas deben permitirle elegir, analizar e interpretar la diversidad fuentes de conocimiento que proveen las tecnologías actuales, con miras al fortalecimiento del contexto en el que se desenvuelve.

3. Es necesario e importante, de acuerdo con todo lo expuesto, realizar el abordaje del currículo para la educación superior de la sociedad actual, lo cual, sintetizando las ideas de Molina (2014), requiere una revisión de las fuentes que proveen el contenido curricular, puesto que el acercamiento a estas ciencias se convierte en un elemento "fundamental" en el proceso curricular. En la Tabla 2 se resumen dichas fuentes.

Tabla 2: Fuentes que proveen el contenido curricular

\begin{tabular}{|c|c|c|c|}
\hline La psicología & La sociología & La antropología & La filosofía \\
\hline $\begin{array}{l}\text { Es esencial para analizar } \\
\text { las diferentes dimensiones } \\
\text { (psicológica, cognoscitiva, } \\
\text { psicomotora y afectiva) del } \\
\text { estudiantado, conocerlo en sus } \\
\text { rasgos, la forma en que enfrenta } \\
\text { el proceso de aprendizaje, la } \\
\text { manera en que interactúa en } \\
\text { diversos grupos y resuelve } \\
\text { situaciones cotidianas. A través de } \\
\text { la psicología, es posible responder } \\
\text { a las siguientes interrogantes: } \\
\text { cuándo aprender, qué es posible } \\
\text { aprender en cada momento y } \\
\text { cómo aprenderlo. }\end{array}$ & $\begin{array}{l}\text { Sobre la sociología, en el } \\
\text { nivel institucional y de aula, } \\
\text { el currículo se vivencia en } \\
\text { un entorno sociohistórico } \\
\text { y cultural, el cual se lee y se } \\
\text { interpreta con ayuda de los } \\
\text { aportes de esta ciencia y provee } \\
\text { elementos que clarifican la } \\
\text { dimensión social que posee el } \\
\text { estudiantado, como ciudadanía } \\
\text { de una sociedad particular. }\end{array}$ & $\begin{array}{l}\text { La educación, el currículo y la } \\
\text { antropología están íntimamente } \\
\text { relacionadas y se influyen } \\
\text { recíprocamente. El punto } \\
\text { de partida de todo sistema } \\
\text { educativo es la concepción que } \\
\text { se tenga del ser humano que } \\
\text { se espera formar; en la base } \\
\text { de todo proceso educativo } \\
\text { hay un modelo antropológico, } \\
\text { todos los comportamientos del } \\
\text { individuo deben comprenderse y } \\
\text { valorarse de acuerdo con el grupo } \\
\text { sociocultural al que este pertenece. }\end{array}$ & $\begin{array}{l}\text { La filosofía recurre } \\
\text { esencialmente a dos de } \\
\text { sus ramas: la axiología y la } \\
\text { epistemología. Con la axiología, } \\
\text { sistematiza las aspiraciones en } \\
\text { cuanto al tipo de ser humano } \\
\text { que se espera alcanzar, esas } \\
\text { aspiraciones se concretan en la } \\
\text { política educativa y desde ahí, } \\
\text { se sustenta el planteamiento } \\
\text { de los fines y objetivos del } \\
\text { sistema educativo, que luego se } \\
\text { concretan en los niveles meso } \\
\text { y micro. }\end{array}$ \\
\hline
\end{tabular}

Nota: Elaboración propia con referentes de Molina (2014).

El análisis y acercamiento a estas disciplinas sugieren retos para la formulación de nuevos PEES. Por ejemplo, desde el punto de vista de la globalización, se observa en el plano económico, una transformación del mundo laboral en el que algunos espacios tradicionales 
doi: http://dx.doi.org/10.15359/ree.23-3.7

URL: http://www.una.ac.cr/educare

CORREO: educare@una.cr

han perdido vigencia y dan paso a posibilidades generadas por nuevas necesidades en el plano social. En el campo social, grandes brechas generacionales, originadas en primera instancia por las influencias mundiales y en el campo cultural, la incursión en novedosas modalidades de aprendizaje con apoyos tecnológicos diversos, que surgen a raíz de la facilidad de compartir en contextos nacionales, regionales e internacionales, experiencias exitosas en el campo. Prensky (2015) señala:

Los alumnos quieren aprender de otra manera, participar activamente en su propio proceso de aprendizaje y conectarlo de forma clara con la realidad. Necesitan pedagogías innovadoras que les hagan ver que el tiempo que pasan en su educación formal tiene valor. Para ello, tanto el currículo como los docentes no deben centrarse en la mera transmisión de conocimientos, sino en dotar a los alumnos de habilidades que les permitan llegar a ser quienes quieren, transformar su entorno y aprender a aprender durante toda la vida. (p. 21)

1. La educación superior, por sí misma, es diversa y atiende un sin número de disciplinas que responden a objetos de estudio específicos; sin embargo, existe una serie de aspectos que son comunes en cuanto a requerimientos sociales y que le dan a cada plan la pertinencia. Aquí, el trabajo interdisciplinario y transdisciplinario de profesionales en la formulación de PEES tiene especial valor. En primera instancia, la interdisciplinariedad como la relación o integración entre disciplinas de naturaleza intrínseca al momento de abordar la propuesta curricular. Así, las disciplinas sustentan el plan de estudios y sus interrelaciones orientan el conocimiento.

2. En adición, como señala Carmona (2004), la transdisciplinariedad plantea estrategias de largo alcance, incluye los enfoques, va más allá de las disciplinas. Es decir, las acciones que se mueven dentro y a través de una determinada disciplina, esto porque permite interpretar la realidad y favorece que personal docente, investigador y estudiantes se unan en las diferentes áreas del conocimiento. Los nuevos diseños curriculares de los PESS, que se realicen con un pensamiento integral, interdisciplinario y transdisciplinario, favorecerán, según Carmona (2004), la "[formación de] profesionales con pensamiento crítico, capaces de abordar planteamientos complejos y, sobre todo, que estén preparados para dar respuestas viables, confiables y con equidad a los planteamientos de la realidad." (párr. 10)

3. Un proceso que otorgue mayor pertinencia y eficacia a los PEES, la flexibilidad curricular, que se expresa en múltiples y variadas formas de instrumentación del plan de estudios y supone sobre las particularidades que conllevan las condiciones de funcionamiento propias de cada institución de educación superior. En la Tabla 3 se presentan algunos ejemplos: 
Tabla 3: Tipos de flexibilidad curricular

\begin{tabular}{|c|c|c|}
\hline Flexibilidad académica & Flexibilidad pedagógica & Flexibilidad administrativa \\
\hline $\begin{array}{l}\text { - El tipo de sistema de créditos. } \\
\text { - Selección de horarios del conjunto de cursos. Según la } \\
\text { Dirección General de Educación Superior para profesionales } \\
\text { de la educación (DGESPE) en } \\
\text { - "Diversificación y ampliación de actividades, espacios y } \\
\text { actores en el proceso formativo" (García y Ortega 2016, p. 4). } \\
\text { - "Sistemas de asesoría y tutoría" (García y Ortega 2016, p. 4). } \\
\text { - "Impulso a procesos de movilidad de los estudiantes" (García } \\
\text { y Ortega 2016, p. 4). } \\
\text { - "Desarrollo de programas de formación en diversas } \\
\text { - "Rodalidades con apoyo de las TIC" (García y Ortega 2016, p. 4). } \\
\text { - Muera del contexto escolar" (García y Ortega 2016, p. 4). } \\
\text { - Modalidad de "formación en diversas modalidades con } \\
\text { - "Moyo de las TIC" (García y Ortega 2016, p. 4). } \\
\text { 2016, p. 4). } \\
\text { - "Diversificación de opciones de titulación" (García y Ortega } \\
\text { 2016, p. 4). }\end{array}$ & $\begin{array}{l}\text { - Relación enseñanza-aprendizaje } \\
\text { específica. } \\
\text { - El estudiantado controla su propio } \\
\text { aprendizaje. } \\
\text { - Los diversos contextos de } \\
\text { aprendizaje favorecen nuevas } \\
\text { formas de interacción y de acceso al } \\
\text { conocimiento. } \\
\text { - Se estructura de forma } \\
\text { personalizada el qué y cómo } \\
\text { de los aprendizajes y espacios } \\
\text { pedagógicos disponibles. } \\
\text { - Se desarrollen competencias en } \\
\text { diversos contextos. } \\
\text { - Estructuras horizontales y } \\
\text { personalizadas. }\end{array}$ & $\begin{array}{l}\text { - Se relaciona con el desarrollo } \\
\text { institucional. } \\
\text { - Brinda mejores medios para } \\
\text { redefinir sus alcances. } \\
\text { - Incluye aprendizajes valiosos } \\
\text { entre un programa a otro. } \\
\text { - Innovaciones en la gestión, la } \\
\text { planificación y la organización } \\
\text { del trabajo académico de } \\
\text { investigación, formación y } \\
\text { proyección institucional. } \\
\text { - Reconstrucción de una } \\
\text { identidad y un centro de } \\
\text { - atención organizacional. }\end{array}$ \\
\hline
\end{tabular}

Nota: Elaboración propia con referentes de Díaz (2002) y García y Ortega (2016).

Por tanto, como indican Elisondo et al. (2016):"como docentes e investigadores de niveles superiores de enseñanza deberemos ocuparnos de pensar en habilidades o procedimientos concretos a favorecer en nuestras interacciones con los alumnos" (p. 229). Se rescata todo el conjunto de acciones descritas para la puesta en marcha de un currículo "necesario" en la educación superior, como un producto real, posible y tangible. No supone, de manera exclusiva, solventar expectativas y demandas sociales, enfrentar retos de pertinencia y globalización, delinear criterios de calidad, entre otros. Se dirije, más que eso, a delinear políticas y lineamientos que orienten la toma de decisiones institucionales, para definir acciones estratégicas específicas con respecto al proceso integral de la evaluación curricular que todo PEES requiere.

La evaluación del currículo se visualiza como un proceso dinámico, continuo y participativo, que permite validar las formas en las que se concretan las intencionalidades del currículo "necesario" que permitan identificar oportunidades de mejora en la oferta. A partir de la evaluación continua del PEES y de las oportunidades de mejora que se generan en la evaluación, aparecen en escena las posibilidades de innovación del currículo y de su gestión.

Si se visualiza como un ciclo, la innovación es fin y principio de la reflexión en la toma de decisiones en materia de planes de estudio y es entendida como producto relevante de la experiencia y el aprendizaje continuo de las instituciones de educación superior, como evidencia del desarrollo y crecimiento del currículo "necesario", como elemento dinámico y dinamizador en la formación profesionales. 
doi: http://dx.doi.org/10.15359/ree.23-3.7

URL: http://www.una.ac.cr/educare

CORREO: educare@una.cr

\section{Conclusiones y recomendaciones}

El estudio presenta una abundante información de los diferentes referentes curriculares que pueden ser considerados en la toma de decisiones al momento de la elaboración de los planes de estudio en el ámbito universitario. No obstante, es importante considerar, para su implementación, la pertinencia y experiencia acumulada de los actores sociales; las innovaciones metodológicas y tecnológicas; la comprensión de los contextos sociales nacionales e internacionales donde se desarrollan; el alto nivel de relevancia para atender las necesidades del contexto, y la capacidad de sistematizar, organizar y coordinar los elementos en la concreción de los planes de estudios en el plano prescrito.

A continuación, se detallan las conclusiones y recomendaciones que surgen de esta investigación, según el objetivo planteado inicialmente y que se desglosa en tres elementos para su análisis: primero, la concepción de currículo de educación superior; segundo, los referentes curriculares por considerar en la toma de decisiones requeridas para la implementación reflexiva de los planes de estudio; y tercero, los retos de la educación superior ante las demandas de la sociedad actual.

En relación con el primero elemento, la conceptualización del currículo en la educación superior se visualiza como la concreción de planes de estudio en el plano prescrito, es decir, es el producto final después una revisión de minuciosa de elementos que se integran según los enfoques curriculares que se utilicen, aunados a una serie elementos que participan activamente durante su elaboración, tales como: recursos financieros, capacidad para integrar los contextos nacionales con los internacionales, capacidad de talento humano, capacidad de infraestructura que corresponda a los principios y fundamentos del plan de estudios, capacidad para incorporar las nuevas tendencias sociales; pero, sobre todo, esta conceptualización contempla que los escenarios educativos universitarios están influenciados por la evolución humana y, por lo tanto, no es un producto acabado sino en contante revisión y actualización. Esto implica el reto de la toma de decisiones curriculares con una alta participación académica, administrativa, estudiantil y de la comunidad donde se desarrolla.

Aunado a lo anterior, cabe destacar que, por la autonomía universitaria y por la naturaleza sustantiva de la educación superior, la conceptualización del currículo universitario esta fortalecida por la investigación, extensión y docencia. Esto permite que la concreción del currículo se realice con cierto nivel de autonomía en el nivel meso (Ornelas, 2008), pero que a su vez puede ser fortalecido por los niveles macro y micro de la educación.

Con respecto al segundo elemento el objetivo del estudio, los referentes curriculares por considerar en la toma de decisiones requeridas para la implementación reflexiva de los planes de estudio, se puede concluir que el estudio permite clasificar 5 grandes grupos de enfoques, clasificados por Eisner y Wallance (1974), Molina (1997), Grundy (1998), Posner (1998) y Sacristán (2010), cada especialista presenta un grupo de enfoques según su naturaleza sustantiva. 
En el caso de Grundy (1998), presenta una distinción entre los enfoques curriculares técnico y práctico, mientras que en el técnico interesa la ejecución del programa por el profesorado y por el producto; el práctico, se enfoca en el proceso de enseñanza-aprendizaje, pero en ambos el profesorado es el núcleo principal. Ante este escenario, también propone el enfoque de transición donde se plantea una relación docente-estudiante más flexible; pero donde sigue siendo el profesorado el responsable de la ejecución curricular. Por otro lado, el enfoque crítico social se orienta a la praxis donde se unifica con un proceso dialéctico, y que de igual manera se considera al profesorado como el único grupo investigador. Estos enfoques presentan una serie de elementos, tal y como se detalla en este artículo, que pueden ser utilizados en aquellos planes de estudios donde la orientación y participación del profesorado es fundamental para desarrollar las habilidades o conocimientos en el estudiantado. Es importante acotar, que el plan de estudios que implemente, de una u otra forma estos enfoques, requerirá ser explícito sobre el perfil docente solicitado y en cuales etapas del plan de estudio se necesita de una participación docente activa.

En el segundo grupo de enfoques (Eisner y Wallance, 1974), se presentan cinco enfoques que aportan una visión curricular distinta entre ellos, sin embargo, cada uno logra brindar aportes importantes. En cuanto al enfoque cognoscitivo, el perfeccionamiento de destrezas intelectuales; el enfoque de relevancia de la reconstrucción social enfatiza en el papel de la educación como transformadora social más que en lo individual; el enfoque tecnológico se centra en el cómo, más que en el qué de la educación; el enfoque autorrealización o experiencia consumatoria se centra en el estudiantado, su autonomía y crecimiento personal, y el enfoque racionalismo académico le da prioridad a la razón. Cada uno de ellos presenta elementos que pueden enriquecer aquellos planes de estudios según sea la perspectiva que se le quiera brindar; por un lado, desarrollar más conocimiento, razón y práctica a través de la tecnología y, por otro, aquellos enfoques que potencian las habilidades de autorrealización y lo social.

Sacristán (2010) propone tres enfoques: el primero, base de experiencias, enfocado en lo académico y que complementa con hora teórica y hora practica; segundo, el legado tecnológico y eficientista, centrado en atender las demandas sociales del mundo laboral y empresarial; y el tercero configurador de práctica, el cual vas más allá del campo laboral para preparar para la transformación social.

Posner (1998), por otro lado, muestra cinco enfoques para diferenciar el currículo. El primero, tradicional, cuyo fin es la transmisión del conocimiento; el experimental, que se basa en la experiencia del estudiantado en todos sus contextos; la estructura de las disciplinas, que se organiza en áreas de formación y disciplinas; conductista, que se centra en el comportamiento por medio de recompensas; y el cognitivo, que se centra en el pensamiento y su significado. Estos enfoques pueden ser muy beneficiosos, si se mezclan entre sí a la hora en elaboración de planes, porque tienen elementos que se pueden interrelacionar, siempre con el cuidado de distinguirlos, conocer su propósito y funcionalidad. 
doi: http://dx.doi.org/10.15359/ree.23-3.7

URL: http://www.una.ac.cr/educare

CORREO: educare@una.cr

Finalmente, Molina (1997), los organiza en cuatro enfoques: el humanismo, se centra en el individuo en lo afectivo y cognitivo; por competencias, orientado en el desempeño en el área ocupacional; constructivismo, donde el sujeto es responsable de construir su propio aprendizaje; y el problematizador, que relaciona los problemas de conocimiento con el contexto donde se desarrollan. Estos últimos tienen una clara identificación de la relación del estudiantado con su propio aprendizaje y su relación social.

La comprensión de estos 22 enfoques, según sus características, permite a los entes gestores del currículo y a equipos investigadores, que participen en la elaboración de planes, valorar cuáles se ajustan mejor a sus requerimientos.

En relación con el tercer y último elemento del objetivo de este artículo: los retos de la educación superior ante las demandas de la sociedad actual, se concluye que esta tiene grandes desafíos. Entre ellos, articular los tres niveles de concreción curricular: macro, meso y micro, para atender las demandas de una sociedad en constante cambio y con dinámicas sociales que están en transformación social.

Los planes de estudio deben responder a estudios minuciosos y que puedan ser revisados a la luz de nuevas tendencias curriculares y otras investigaciones interdisciplinarias y transdisciplinarias que nutran la teoría y la práctica. Por esta razón, la universidad no debe ser un ente aislado de su realidad social sino; por lo contrario, tener una amplia participación a fin de comprender de cerca las dinámicas que confluyen y sus implicaciones sobre la realidad social.

Los cambios de cara a los procesos de desarrollo curricular en la educación superior deben contemplar tanto a los grupos participantes internos como al personal docente y administrativo y a estudiantes, y a los externos, como, por ejemplo, los entes empleadores.

El éxito en la construcción de nuevos modelos de planes de estudios radica en comprender que este es un proceso de construcción colectiva, donde se toma en cuenta la inclusión social, respeto por la diversidad, la influencia de un mundo que se interconecta, y que dé como resultado un currículo necesario, posible y tangible (Elisondo et al, 2016).

\section{Referencias}

Elisondo R., de la Barrera, M. L., Rigo, D. Y., Kowszyk, D. I., Fagotti, E., Ricetti, A. y Siracusa, M. R. (2016). Estudiantes hoy, entre Facebook, Google y metacognición. Ideas para innovar en la educación superior. REDU Revista de docencia universitaria, 14(1), 225-244. doi: https:// doi.org/10.4995/redu.2016.5800

Campos, S. (2011). Enenfoquescurricularespraxiológicos [Diapositivasen PowerPoint]. Recuperado de https://issuu.com/susanacampos4/docs/enfoques curriculares praxiologicos 
Carmona, M. A. (2004). Transdisciplinariedad: Una propuesta para la educación superior en Venezuela. Revista de Pedagogía, 25(73). Recuperado de http://www.scielo.org.ve/scielo. php?script=sci arttext\&pid=S0798-97922004000200007\&lng=es\&tIng=es

Castillo, L. (2003). Enfoques o concepciones curriculares. Santiago: Instituto Profesional de Providencia.

Castro, N. (2010). Metodologías y enfoques curriculares CONESUP [Mensaje en un blog]. Recuperado de http://metodologiayenfoqueconesup.blogspot.com/

Cazares, M. (s. f.). Una reflexión teórica del currículum y los diferentes enfoques curriculares. Recuperado de http://moodle2.unid.edu.mx/dts cursos mdl/lic/EEL/PMP/AM/09/Una reflexion.pdf

Coll, C., Martín, E., Mauri, T., Miras, M., Onrubia, J., Solé, I. y Zabala, A. (1999). El constructivismo en el aula. Barcelona: Graó. Recuperado de http://www.terras.edu.ar/biblioteca/3/3Losprofesores-y-la-concepcion.pdf

Díaz, M. (2002). Flexibilidad y educación superior en Colombia. Bogotá: ICFES. Recuperado de http://acreditacion.unillanos.edu.co/CapDocentes/contenidos/dis ambientes metodos pedagogicos/Memoria3/flexibilidad educacion colombia.PDF

Duarte, J. E., Roberto, J., Moreira, Á. y Valdés, D. R. (2003). Investigación acción en el aula. Estudio etnográfico sobre la pertinencia del currículo en el proceso de enseñanza del idioma inglés en el séptimo grado de los centros escolares: Centro escolar profesor Rodrigo Flores, Turín, Ahuachapán y complejo educativo Colonia Río Zarco, Santa Ana (Tesis de licenciatura), Universidad de El Salvador. Recuperado de http://ri.ues.edu.sv/14798/

Eisner, E.W.y Vallance, E. (Eds.). (1974). Conflicting conceptions of curriculum. Berkeley:McCutchen.

Eraso, G. (2008). Proyecto pedagógico disciplinar. San Juan de Pasto: Institución Universitaria CESMAG. Recuperado de http://biblioteca.iucesmag.edu.co/digital/ memoria/9789588439044/9789588439044.pdf

García, A., Edel, R. y Escalera, M. E. (2010). La enseñanza de la matemática financiera (Un modelo didáctico mediado por TIC). Recuperado de http://www.eumed.net/libros/2010f/867/ index. $\mathrm{Htm}$

García, A. y Ortega, T. (2016). Un estudio de caso: La escuela normal ante la formación de cuerpos académicos. En Memoria académica compartimos lo que sabemos (pp. 1-21). Recuperado de http://www.memoria.fahce.unlp.edu.ar/trab eventos/ev.8450/ev.8450.pdf

González, M. I. (2006). Currículo basado en competencias: Una experiencia en educación universitaria. Educación y Educadores, 9(2), 95-117. Recuperado de http://www.scielo.org. co/pdf/eded/v9n2/v9n2a08.pdf 
doi: http://dx.doi.org/10.15359/ree.23-3.7

URL: http://www.una.ac.cr/educare

CORREO: educare@una.cr

Grundy, S. (1998). Producto o praxis del curriculum. Madrid: Ediciones Morata.

Herrera, V., Montes, I., Santiago, E. y Tapia, M. (2017). Diseño de un plan de mejoramiento como propuesta de intervención para el fortalecimiento de los procesos curriculares de una institución educativa (Tesis de maestría). Recuperado de http://manglar.uninorte.edu.co/ bitstream/handle/10584/7559/dise\%C3\%B1odeunplan.pdf?sequence=1\&isAllowed=y

Jiménez, L. (2008). Enfoque curricular centrado en la persona. Revista Educación, 32(1), 63-76. doi: https://doi.org/10.15517/revedu.v32i1.524

Juliao, C. G. (2014). Una pedagogía praxeológica. Bogotá: Corporación Universitaria Minuto de Dios. Recuperado de http://cnbmtucuman.edu.ar/cnbm files/biblioteca doc/Una Pedagogia Praxeologica-Carlos German Juliao Vargas.pdf

Luna, E. A. y López, G. A. (2011). El currículo: Concepciones, enfoques y diseño. Revista Unimar, 58, 65-76. Recuperado de http://www.umariana.edu.co/ojs-editorial/index.php/unimar/ article/download/217/193

Molina, Z. (1997). Planeamiento didáctico. Fundamentos, principios, estrategias y procedimientos para su desarrollo. San José, Costa Rica: EUNED.

Molina, Z. (2014). Fundamentos del currículo. San José, Costa Rica: EUNED.

Navas, M. E. (2012). Origen del currículo. En M. Navas (Comp.), Proyecto de investigación: Evolución en el campo del currículo en Colombia Región Caribe 1970-2010 (pp. 15-48). Recuperado de https://issuu.com/cadecartagena/docs/evolucion del curriculo

Ornelas, J. (2008). Reflexiones en torno a la autonomía universitaria. La reforma universitaria. Desafíos y perspectivas noventa años después. Buenos Aires: CLACSO.

Pardo, M. (2013). Concepciones o enfoques curriculares [Diapostivias en Prezi]. Recuperado de https://prezi.com/y2apw6wbo1gz/concepciones-o-enfoques-curriculares/

Posner, G. J. (1998). Análisis del currículo. Bogotá: McGraw-Hill.

Prensky, M. (2015). El mundo necesita un nuevo currículo: Habilidades para pensar, crear, relacionarse y actuar. Argentina: Ediciones SM.

Sacristán, J. G. (Comp.). (2010). Saberes e incertidumbres sobre el currículum. Madrid: Ediciones Morata.

Velasco, J. E. (Comp.). (2014). Dirección de educación abierta y a distancia y virtualidad. Licenciatura en educación básica. Diseño curricular. Colombia: CECAR. Recuperado de https://docplayer. es/68098810-Direccion-de-educacion-abierta-y-a-distancia-y-virtualidad-licenciaturaen-educacion-basica-diseno-curricular.html 
doi: http://dx.doi.org/10.15359/ree.23-3.7

URL: http://www.una.ac.cr/educare

Yagual, J. L. (2015). Modelo de convivencia para el fortalecimiento de la equidad de género de los niños del quinto año de la escuela de educación básica "Gral. César Rohón Sandoval" de la Parroquia Anconcito, en el cantón salinas, durante el período lectivo 2014-2015 (Tesis de licenciatura). Universidad Estatal Península de Santa Elena, Ecuador. Recuperado de http:// repositorio.upse.edu.ec/bitstream/46000/3713/1/UPSE-TEB-2015-0294.pdf

Zúñiga, G. (2011). Concepciones teóricas del diseño curricular a partir de un enfoque por competencias para la formación laboral del técnico medio en informática. Cuadernos de Educación y Desarrollo, 3(27). Recuperado de http://www.eumed.net/rev/ced/27/gzc3.htm 